\title{
Evaluation of Norovirus Reduction in Environmentally Contaminated Pacific Oysters During Laboratory Controlled and Commercial Depuration
}

\author{
Agnieszka Rupnik ${ }^{1} \cdot$ William Doré ${ }^{1} \cdot$ Leon Devilly ${ }^{1} \cdot$ James Fahy $^{1} \cdot$ Amy Fitzpatrick $^{1} \cdot$ Wiebke Schmidt $^{1} \cdot$ Kevin Hunt $^{2}$. \\ Francis Butler ${ }^{2}$. Sinéad Keaveney ${ }^{1}$ (i)
}

Received: 9 November 2020 / Accepted: 23 January 2021 / Published online: 2 March 2021

(c) The Author(s) 2021

\begin{abstract}
Norovirus contamination of oysters is the lead cause of non-bacterial gastroenteritis and a significant food safety concern for the oyster industry. Here, norovirus reduction from Pacific oysters (Crassostrea gigas), contaminated in the marine environment, was studied in laboratory depuration trials and in two commercial settings. Norovirus concentrations were measured in oyster digestive tissue before, during and post-depuration using the ISO 15216-1 quantitative real-time RTPCR method. Results of the laboratory-based studies demonstrate that statistically significant reductions of up to $74 \%$ of the initial norovirus GII concentration was achieved after 3 days at $17-21{ }^{\circ} \mathrm{C}$ and after 4 days at $11-15{ }^{\circ} \mathrm{C}$, compared to $44 \%$ reduction at $7-9{ }^{\circ} \mathrm{C}$. In many trials norovirus GII concentrations were reduced to levels below 100 genome copies per gram $\left(\mathrm{gcg}^{-1}\right.$; limit of quantitation; LOQ). Virus reduction was also assessed in commercial depuration systems, routinely used by two Irish oyster producers. Up to $68 \%$ reduction was recorded for norovirus GI and up to $90 \%$ for norovirus GII reducing the geometric mean virus concentration close to or below the LOQ. In both commercial settings there was a significant difference between the levels of reduction of norovirus GI compared to GII $(p<0.05)$. Additionally, the ability to reduce the norovirus concentration in oysters to < LOQ differed when contaminated with concentrations below and above $1000 \mathrm{gcg}^{-1}$. These results indicate that depuration, carried out at elevated $\left(>11^{\circ} \mathrm{C}\right)$ water temperatures for at least 3 days, can reduce the concentration of norovirus in oysters and therefore consumer exposure providing a practical risk management tool for the shellfish industry.
\end{abstract}

Keywords Depuration · Human norovirus · Risk management · Oysters · RT-qPCR · ISO 15216-1

\section{Introduction}

Norovirus infections are the most common cause of nonbacterial gastroenteritis worldwide (Marshall et al. 2003; Marshall and Bruggink 2011). Filter-feeding bivalve molluscan shellfish such as mussels, clams and oysters can become contaminated with human norovirus when grown in areas impacted by human sewage discharges. Such shellfish present a recognised public health risk when consumed raw or lightly cooked (Bellou et al. 2013) and regulations exist

Sinéad Keaveney

Sinead.Keaveney@marine.ie

Marine Institute, Rinville, Oranmore, Ireland

2 Centre for Food Safety, University College Dublin, Dublin, Ireland throughout the world to manage their production. In Europe, regulatory controls predominantly centre around the sanitary classification of harvesting areas into three categories, A, B or C, based on increasing Escherichia coli concentrations (Anonymous 2004, 2019). Each classification category calls for differing degrees of post-harvest treatment: from no additional treatment for shellfish harvested from class A waters, to relay and depuration for shellfish grown in class $\mathrm{C}$ areas. One of the most widely practiced post-harvest treatments is depuration, whereby bivalve shellfish undergo self-purification in land-based tanks of clean seawater. The process was originally designed in the beginning of the twentieth century to prevent bacterial illness associated with shellfish consumption.

In order to comply with EU regulations shellfish harvested from class B areas, accounting for approximately $60 \%$ of overall oyster production across the EU (EFSA 2019) 
must be depurated prior to going to market. Despite these regulatory obligations virtually eliminating bacterial illness associated with bivalve shellfish, there are many reports of such product causing outbreaks of viral illness (Morse et al. 1986; Chalmers and McMillan 1995; Lee et al. 1999; Kingsley et al. 2002; Baker et al. 2010; LeBlanc et al. 2016). In particular, such outbreaks have been associated with the consumption of oysters (Le Guyader et al. 2010; Westrell et al. 2010; Alfano-Sobsey et al. 2011; Rajko-Nenow et al. 2013). Oysters harvested from A classified areas, where post-harvest treatment is not mandatory, have also been associated with outbreaks of illness (Doré et al. 2010). Oysters present additional risks due to a number of factors such as being grown in intertidal areas often impacted by sewage and being consumed raw or only lightly cooked. This has resulted in an increasing number of commercial oyster producers in Ireland and elsewhere that harvest from A classified production areas to include depuration as an extra step in their HACCP (Hazard Analysis and Critical Control Point) or risk management procedures (Rupnik et al. 2018).

Minimum time and water temperature used in commercial depuration are not stipulated in EU regulation. In Ireland, it is recommended that depuration should be carried out for a minimum of $42 \mathrm{~h}$ with a water temperature of no less than $8{ }^{\circ} \mathrm{C}$ (Anonymous 2018). This treatment has been shown to consistently reduce $E$. coli concentrations to below the regulatory limit of $230 \mathrm{MPN} / 100 \mathrm{~g}$, but not to reduce norovirus to the same extent (Schwab et al. 1998; McLeod et al. 2009). However, some studies have indicated that depuration time and seawater temperature are both factors that may influence virus reduction during bivalve shellfish depuration (Lees et al. 2010). The potential for norovirus reduction in oysters during enhanced depuration procedures was identified previously by this group (Rupnik et al. 2018) prompting this study to investigate norovirus reduction in oysters under controlled laboratory conditions.

Artificial contamination of shellfish with viral pathogens is a common approach to studying depuration processes and has been described previously (Muniain-Mujika et al. 2002; Choi and Jiang 2005; Nappier et al. 2008; McLeod et al. 2009; Polo et al. 2014b). As shellfish are known to efficiently bioaccumulate viruses in as little as several hours (Flannery et al. 2012; Souza et al. 2013, 2018; Pilotto et al. 2019), this approach allows for a rapid generation of animals contaminated with one or multiple viral strains. Concentrations as high as $10^{11}$ genome copies per gram $\left(\mathrm{gcg}^{-1}\right)$ of murine norovirus (MNV1) were achieved during 24h bioaccumulation in C. gigas by Pilotto et al. (2019), whereas both GI and GII human norovirus genogroups, simultaneously bioaccumulated in C. gigas oysters to $10^{6} \mathrm{gcg}^{-1}$ (Maalouf et al. 2011). Maximum reductions of the norovirus concentrations in such artificially contaminated shellfish were previously reported in the region of $1-1.2 \log _{10}$ unit (equivalent to
90-94\% reduction) and based on that evidence the process was deemed ineffective (McLeod et al. 2017). However, the initial viral loads in such conditioned animals would be considered to be much higher than those seen in oysters from classified production areas across Europe as confirmed by the EFSA baseline survey conducted between November 2016 and October 2018 (EFSA 2019). Much less is therefore known about the efficacy of norovirus reduction of environmentally contaminated oysters from classified production areas under controlled laboratory conditions or in commercial operations. Evidence for viral reduction during modified depuration procedures was reported by (Doré et al. 1998) using FRNA bacteriophage where a significant reduction in FRNA bacteriophage was observed when water temperature was increased to $18^{\circ} \mathrm{C}$. The introduction of quantitative realtime PCR for the detection and quantification of norovirus in bivalve shellfish, particularly the method described in ISO 15216-1:2017 (Anonymous 2017), has been an important step in the area of risk management of norovirus. This tool has allowed better understanding of the relative differences in norovirus concentrations when applying risk management procedures (Rupnik et al. 2018), as well as understanding the concentrations of norovirus found in classified production areas across the EU (EFSA 2019).

As far as the authors are aware, this is the first study using the ISO 15216-1 standard method based on real-time RTPCR to measure norovirus RNA concentrations in oysters contaminated in their natural environment during controlled laboratory depuration studies and enhanced commercial depuration procedures. Our aim was to provide evidence to support the hypothesis that appropriate depuration conditions can be successfully used in the commercial setting as part of risk management measures to reduce the risk to consumer by decreasing the norovirus concentrations in market-ready shellfish.

\section{Materials and Methods}

\section{Oysters}

Triploid Pacific oysters (Crassostrea gigas) contaminated with norovirus in their growing areas were used in all laboratory depuration trials. Oysters from a commercial classified production area were monitored for norovirus GI and GII contamination on a weekly basis and results of the monitoring were used to schedule the depuration experiments. Once the norovirus concentrations increased to, or above, $300 \mathrm{gcg}^{-1}$ a batch of oysters were harvested, washed and transported to the laboratory within $27 \mathrm{~h}$ under temperaturecontrolled conditions $\left(<15^{\circ} \mathrm{C}\right)$. On receipt in the laboratory, oysters were stored in dry, cool conditions and used in depuration trials within $24 \mathrm{~h}$. 


\section{Laboratory Depuration Trials}

Two $0.6 \mathrm{~m}^{3}$ tanks (Depur Systems, UK) were filled with 400-450 L potable mains water and $15 \mathrm{~kg}$ of Seamix Artificial Sea Water salt mix $\left(\mathrm{NaCl} 66.1 \% ; \mathrm{MgSO}_{4} 16.3 \% ; \mathrm{MgCl}_{2}\right.$ $12.7 \%$; $\mathrm{CaCl}_{2} 3.3 \%$ and $\mathrm{KCl} 1.6 \%$; Peacock Salt, UK) was added to each and stirred until fully dissolved. The amount of salt added increased water salinity to between 28 and 32 ppt mimicking that of the estuary. This artificial seawater was circulated in the tank overnight to fully equilibrate before depuration experiments commenced. Water temperature was maintained within $1{ }^{\circ} \mathrm{C}$ of target temperature with a combination of $300 \mathrm{~W}$ aquarium heaters placed directly in the tank and an externally located $750 \mathrm{~W}$ water chiller (D\&D, DC750). Bar sprinklers located above one side wall of the tank were used for aeration and water flow was maintained using an external pump at 2000-2200 L/h. One 36 W UV-C lamp fitted inline on each tank was used to sterilise the circulating water. Dissolved oxygen levels were measured once daily using a hand-held OxyGuard device. Oysters were placed loosely in shallow plastic trays, approximately $70-80$ animals per tray. In total, four trays per tank (between 280 and 320 oysters) were placed in each depuration tank and subjected to depuration. Triplicate samples of 12 oysters were collected at commencement of the experiment (Day 0) and at 24-h intervals thereafter (Days 1-7). Oysters were stored at $4{ }^{\circ} \mathrm{C}$ for up to $24 \mathrm{~h}$ before further processing. A full depuration cycle was run for 7 days (approx.168 h) after which the tanks were drained, cleaned, and filled with freshly prepared artificial sea water before the next experiment.

\section{Shelf Life Test}

Forty-five oysters remaining in the depuration tanks after completion of the laboratory trials at $8{ }^{\circ} \mathrm{C}$ and $18{ }^{\circ} \mathrm{C}$ were placed on shallow trays and refrigerated $\left(5^{\circ} \mathrm{C}\right)$ for 4 weeks. Once a week, oysters were inspected and any gaping or unresponsive to percussion animals were counted and disposed of.

\section{Commercial Depuration}

Paired samples, pre- and post-depuration, were collected from two separate oyster producers between January 2018 and December 2019 (Producer A) and February 2018 to April 2019 (Producer B). Producer A operates in a class A area, whilst Producer B operates in an area with a seasonal A classification during December through to March and class B for the rest of the year. Depuration is routinely used in both facilities with Producer A typically depurating oysters for 7 days with an average water temperature of $14{ }^{\circ} \mathrm{C}$ (ranging from 12 to $16^{\circ} \mathrm{C}$ between the depuration cycles). Producer B performs depurations typically for $72 \mathrm{~h}$ at an accurately controlled stable $18{ }^{\circ} \mathrm{C}$. Twentyfour and 22 depuration cycles carried out by Producer A and $\mathrm{B}$, respectively, were examined. Pre-depuration oyster samples were collected on the day depuration commenced and were followed by a second, paired sample taken after the completion of the depuration process. Each sample consisted of 12 live animals that were transported into the laboratory under chilled conditions $\left(<15^{\circ} \mathrm{C}\right)$ within $27 \mathrm{~h}$ (Producer A) or $5 \mathrm{~h}$ (Producer B). Upon arrival, oysters were stored at $4{ }^{\circ} \mathrm{C}$ for up to $24 \mathrm{~h}$ before processing. When evaluating the commercial depuration processes, both norovirus genogroups were quantified in the pre-depuration samples. Samples in which the virus concentration was greater than $150 \mathrm{gcg}^{-1}$ for at least one genotype were selected and subsequently followed with a sample taken after completion of depuration. This allowed for concurrent analysis of the effect of depuration on both norovirus genotypes in oysters.

\section{Norovirus Detection in Oysters}

\section{Preparation of Oyster Samples for Norovirus Analysis}

Oysters were analysed for the presence of norovirus GI and GII in accordance with ISO 15216-1:2017 (Anonymous 2017). Briefly, oysters were cleaned under running potable water. Ten oysters per sample were shucked and the digestive tissues (DT) dissected out. The dissected DT was finely chopped using a sterile razor blade and mixed well. Two grams of DT were then spiked with $10 \mu \mathrm{l}$ of the internal process control (IPC) virus (Mengo virus strain $\mathrm{MC}_{0}$ ) for evaluation of virus extraction efficiency similar to that described by (Costafreda et al. 2006) and treated with $2 \mathrm{ml}$ Proteinase $\mathrm{K}\left(100 \mu \mathrm{g} \mathrm{ml}^{-1}\right)$. Samples were incubated at $37{ }^{\circ} \mathrm{C}$ for $60 \mathrm{~min}$ with shaking at $150 \mathrm{rpm}$ followed by $15 \mathrm{~min}$ at $60^{\circ} \mathrm{C}$. Finally, after centrifugation at $3000 \times g$ for $5 \mathrm{~min}$, supernatants were retained for RNA extraction.

\section{Viral RNA Extraction}

RNA was extracted from $500 \mu \mathrm{l}$ of the DT supernatants using NucliSENS ${ }^{\circledR}$ magnetic extraction reagents (bioMérieux) and the NucliSENS ${ }^{\circledR}$ MiniMAG ${ }^{\circledR}$ extraction platform and eluted into $100 \mu \mathrm{l}$ of elution buffer. RNA extracts were stored at $-80{ }^{\circ} \mathrm{C}$ until the RT-qPCR analysis was conducted. RNA was also extracted from $10 \mu$ of the IPC sample for evaluation of extraction efficiency. A single negative extraction control (water only) was processed alongside the oyster samples. 


\section{Determination of the Norovirus Concentration Using One-Step RT-qPCR}

Oysters were analysed for the norovirus concentrations using standardised quantitative real-time reverse transcription PCR (RT-qPCR) (Anonymous 2017). RT-qPCR analysis was carried out using the Applied Biosystems AB7500 instrument (Applied Biosystems, Foster City, CA) and the RNA Ultrasense one-step RT-qPCR system (Invitrogen). The reaction was prepared by combining $5 \mu$ of the extracted RNA sample and $20 \mu \mathrm{l}$ of the reaction mix containing $500 \mathrm{nM}$ forward primer, $900 \mathrm{nM}$ reverse primer, $250 \mathrm{nM}$ sequence specific probe, $1 \times$ ROX reference dye and $1.25 \mu$ of enzyme mix. Previously described primers QNIF4 (da Silva et al. 2007), NV1LCR (Svraka et al. 2007) and TM9 probe (Hoehne and Schreier 2006) were used for the detection of norovirus GI, and QNIF2 (Loisy et al. 2005), COG2R (Kageyama et al. 2003) and QNIFS probe (Loisy et al. 2005) were used for the detection of norovirus GII. The Mengo110, Mengo209 primers and Mengo147 probe were used in IPC assay (Pintó et al. 2009). The 96-well optical reaction plate was incubated at $55{ }^{\circ} \mathrm{C}$ for $60 \mathrm{~min}, 95{ }^{\circ} \mathrm{C}$ for $5 \mathrm{~min}$, and then 45 cycles of PCR were performed, with 1 cycle consisting of $95{ }^{\circ} \mathrm{C}$ for $15 \mathrm{~s}, 60{ }^{\circ} \mathrm{C}$ for $1 \mathrm{~min}$, and $65^{\circ} \mathrm{C}$ for $1 \mathrm{~min}$. All samples were analysed for norovirus GI and GII in duplicate. All control materials used in the RT-qPCR assays were prepared as described by Flannery et al. (2012). To enable quantification of norovirus RNA in copies per $\mu \mathrm{l}$, a $\log _{10}$ dilution series of the norovirus GI and GII DNA plasmids (ranging from $1 \times 10^{1}$ to $1 \times 10^{5}$ copies $/ \mu$ l) were included in duplicate on each RT-qPCR run. The number of RNA copies in norovirus-positive samples was determined by comparing the $C_{T}$ value to the standard curves. The final concentration was then adjusted to reflect the volume of sample analysed and expressed as the number of detectable virus genome copies per gram of DT. The presence of inhibitors was checked by spiking an additional $5 \mu$ of each sample RNA with $1 \mu$ l of either norovirus GI or norovirus GII external control RNA (ECRNA; $10^{5}$ RNA transcripts/ $\mu$ l). The threshold cycle $\left(C_{T}\right)$ value obtained for samples spiked with the ECRNA was compared to the results obtained in the absence of the sample ( $5 \mu$ l of water used instead) and used to estimate RT-PCR inhibition expressed as a percentage. In accordance with ISO 15216-1:2017. Oyster samples with RT-PCR inhibition below the $75 \%$ were accepted for inclusion in this study. Extraction efficiency was assessed by comparing the $C_{T}$ value of the sample spiked with IPC virus to a standard curve obtained by preparing $\log _{10}$ dilutions of the RNA extracted from $10 \mu \mathrm{l}$ Mengo virus and was subsequently expressed as percentage extraction efficiency. Samples with the extraction efficiency greater than $1 \%$ were accepted for inclusion in this study (Anonymous 2017). No template controls (water only) and negative extraction controls (blank sample carried through the RNA extraction step) were included in each RT-PCR analysis to control for cross-contamination.

\section{Analysis of Results}

\section{LOD and LOQ}

The limits of detection (LOD) and quantification (LOQ) for Norovirus GI and GII were established based on European Union Reference Laboratory (EURL) for monitoring the bacteriological and viral contamination of bivalve molluscs guidance using dilution series of oyster digestive gland material contaminated with both, norovirus GI and GII (CEFAS 2016). The LOD and LOQ for norovirus GI and GII was determined as 20 and $100 \mathrm{gcg}^{-1}$, respectively. For statistical analysis, and in order to facilitate geometric mean calculation, samples in which norovirus was not detected were assigned a value of $10 \mathrm{gcg}^{-1}$ (half of the LOD) and those that tested positive below $100 \mathrm{gcg}^{-1}$ (<LOQ) were assigned a value of $50 \mathrm{gcg}^{-1}$ (half of LOQ).

\section{Relative Concentrations}

Due to variances in starting norovirus concentration, and to allow for comparison between experiments and statistical analysis, all concentrations were converted to values relative to Day 0 (initial load), as follows: $C_{\mathrm{Ri}}=C_{\mathrm{i}} / C_{0}$, where $C_{\mathrm{Ri}}$ - Relative concentration of sample $i ; C_{\mathrm{i}}$-norovirus concentration $\mathrm{gcg}^{-1}$ obtained for sample $i$ using RTqPCR and $C_{0}$-geometric mean of initial load concentration in a given experiment. For example, 2023, 1781 and 1459 norovirus GII $\mathrm{gcg}^{-1}$ were detected in samples A, B and $\mathrm{C}$ collected at Day 0 giving a geometric mean of 1739 norovirus GII $\mathrm{gcg}^{-1}$. Therefore, the relative result for sample $\mathrm{A}=2023 \mathrm{gcg}^{-1} / 1739 \mathrm{gcg}^{-1}=1.163$; sample $\mathrm{B}=1781$ $\mathrm{gcg}^{-1} / 1739 \mathrm{gcg}^{-1}=1.024$ and sample $\mathrm{C}=1459 \mathrm{gcg}^{-1} / 1739$ $\mathrm{gcg}^{-1}=0.839$. This principle was applied to all samples.

\section{Assigning of Data for Laboratory Depuration Trials}

Norovirus test results were assigned into 3 separate groups based on the water temperature used in a given depuration trial: Low-depuration experiments carried out at $8 \pm 1{ }^{\circ} \mathrm{C}$ $(n=5)$; Medium-depuration experiments carried out at 12 or $14{ }^{\circ} \mathrm{C}\left( \pm 1{ }^{\circ} \mathrm{C} ; n=3\right)$ and High-depuration experiments carried out at 18 or $20^{\circ} \mathrm{C}\left( \pm 1^{\circ} \mathrm{C} ; n=7\right)$.

\section{Statistical Analysis}

$\mathrm{R}$ (version 3.6.0) using the libraries 'car' and 'PMCMR' was used for statistical analysis. The normality of the data was tested by performing the Shapiro-Wilk test and the Levene 
test was used to evaluate the homogeneity of variances. To evaluate the differences between three temperatures conditions (low, medium and high) during the depuration study a Kruskal-Wallis rank ANOVA with the pairwise test for multiple comparison of mean rank sums (Dunn's test) as posthoc tests was used. To test the difference of norovirus concentrations during commercial depuration the Mann-Whitney test was applied. The significance level for all statistical analysis was set at $p \leq 0.05$.

\section{Results}

\section{Laboratory Depuration Trials}

Stable conditions in the depuration tanks were maintained throughout each experiment with dissolved oxygen $\left(\mathrm{DO}_{2}\right)$ levels in excess of $80 \%$ in all trials. Norovirus GI concentrations detected in $C$. gigas before depuration were either below or close to the limit of quantification (LOQ) of the test $\left(100 \mathrm{gcg}^{-1}\right)$ and therefore were excluded from further analysis in this study. Before depuration, norovirus GII concentrations in the environmentally contaminated oysters ranged between 178 and 16,426 norovirus GII gcg ${ }^{-1}$ with a geometric mean of 906 norovirus GII gcg ${ }^{-1}$ (Table 1).

Norovirus GII reduction in oysters during laboratory experiments are shown in Fig. 1. First indications of norovirus GII reduction in the medium and high temperature conditions were visible during the initial $24 \mathrm{~h}$ (Fig. 1). Virus reduction continued until day 3 at the high temperature conditions and until day 4 at the medium temperature conditions. Maximum reduction of norovirus GII was achieved by day 3 in the high temperature trials with relative virus concentration reduced to $0.26 \pm 0.11$ (reduction of $74 \%$ or $0.59 \log _{10}$ units). A similar degree of reduction was observed in the medium temperature trials on day 4 with relative concentration reduced to $0.27 \pm 0.32$ (reduction of $73 \%, 0.57 \log _{10}$ units). By contrast, norovirus GII concentrations were not reduced in oysters depurated under low temperature for the first 2 days of depuration. In fact, an increase in norovirus GII concentration was observed in these oysters at day 1 (relative concentration $1.35 \pm 0.33$ ) and the first signs of virus concentration reduction were only observed at day 3 . The maximum reduction of the initial viral load to $0.65 \pm 0.29$ (reduction of $44 \%$ or $0.25 \log _{10}$ units) was observed under low temperature conditions by day 4. Non-parametric Kruskal-Wallis ANOVA showed that there were significant differences in the norovirus GII concentrations observed between the low and high temperature $(p<0.001)$ and between low and medium temperature conditions $(p<0.001)$, but not between medium and high water temperatures $(p=0.14)$.

Norovirus GII reductions during all depuration trials conducted at medium and high water temperatures displayed a two-phase virus reduction kinetic. After the initial rapid reduction of norovirus GII, the rate of depuration decreased and no further significant reduction was observed between days 3 and 7 or days 4 and 7 for high and medium temperatures, respectively (Fig. 1). The two-phase virus reduction kinetic was not evident in the low temperature trials, with a delayed and shortened viral reduction stage.

No oyster mortalities were observed during the first 2 weeks of shelf life test conducted upon completion of the depuration experiments with all oysters responding to
Table 1 Norovirus GII concentrations measured in Pacific oysters during laboratory depuration trials

\begin{tabular}{|c|c|c|c|c|c|c|c|c|c|}
\hline \multirow[t]{2}{*}{ Experiment } & \multirow{2}{*}{$\begin{array}{l}\text { Water } \\
\text { temperature } \\
{\left[{ }^{\circ} \mathrm{C}\right]}\end{array}$} & \multicolumn{8}{|c|}{ Time point $\left[\right.$ days]/norovirus GII concentration $\left[\mathrm{gcg}^{-1}\right]$} \\
\hline & & 0 & 1 & 2 & 3 & 4 & 5 & 6 & 7 \\
\hline 1 & 8 & 16,426 & 15,792 & 7803 & 7463 & 10,742 & 5443 & 11,210 & 7558 \\
\hline 2 & 8 & 290 & 310 & 284 & 142 & $<\mathrm{LOQ}$ & 249 & 147 & 225 \\
\hline 3 & 8 & 5573 & 14,505 & 7428 & 5981 & 2965 & 3334 & 3548 & 2293 \\
\hline 4 & 8 & 1739 & 1970 & 2309 & 1601 & 2122 & 4798 & 2087 & 3020 \\
\hline 5 & 8 & 850 & 1247 & 956 & 467 & 662 & 888 & 512 & 606 \\
\hline 6 & 12 & 452 & 143 & 231 & 202 & $<\mathrm{LOQ}$ & 219 & 181 & $<\mathrm{LOQ}$ \\
\hline 7 & 12 & 405 & 234 & 193 & $<\mathrm{LOQ}$ & $<\mathrm{LOQ}$ & $<\mathrm{LOQ}$ & $<\mathrm{LOQ}$ & $<\mathrm{LOQ}$ \\
\hline 8 & 14 & 1739 & 2465 & 1451 & 1442 & 1599 & 1595 & 1813 & 1248 \\
\hline 9 & 20 & 452 & 129 & 183 & 110 & $<\mathrm{LOQ}$ & $<\mathrm{LOQ}$ & $<\mathrm{LOQ}$ & $<\mathrm{LOQ}$ \\
\hline 10 & 18 & 405 & 236 & 147 & $<\mathrm{LOQ}$ & $<\mathrm{LOQ}$ & $<\mathrm{LOQ}$ & $<\mathrm{LOQ}$ & $<\mathrm{LOQ}$ \\
\hline 11 & 18 & 178 & 102 & $<\mathrm{LOQ}$ & $<\mathrm{LOQ}$ & $<\mathrm{LOQ}$ & $<\mathrm{LOQ}$ & $<\mathrm{LOQ}$ & $<\mathrm{LOQ}$ \\
\hline 12 & 20 & 178 & $<\mathrm{LOQ}$ & $<\mathrm{LOQ}$ & $<\mathrm{LOQ}$ & $<\mathrm{LOQ}$ & $<\mathrm{LOQ}$ & $<\mathrm{LOQ}$ & $<\mathrm{LOQ}$ \\
\hline 13 & 20 & 290 & 168 & $<\mathrm{LOQ}$ & $<\mathrm{LOQ}$ & $<\mathrm{LOQ}$ & $<\mathrm{LOQ}$ & 224 & 233 \\
\hline 14 & 20 & 5573 & 4670 & 5896 & 2296 & 2244 & 1769 & 1513 & 2054 \\
\hline 15 & 18 & 850 & 845 & 389 & 365 & 522 & 474 & 301 & 310 \\
\hline
\end{tabular}


Fig. $1 \log _{10}$ reduction (lines) of norovirus GII at 3 water temperature regimes studied and norovirus GII concentrations (bars) detected in oysters during laboratory depuration trials. Results shown as relative to norovirus GII concentration at day 0 , error bars \pm geometric standard deviation

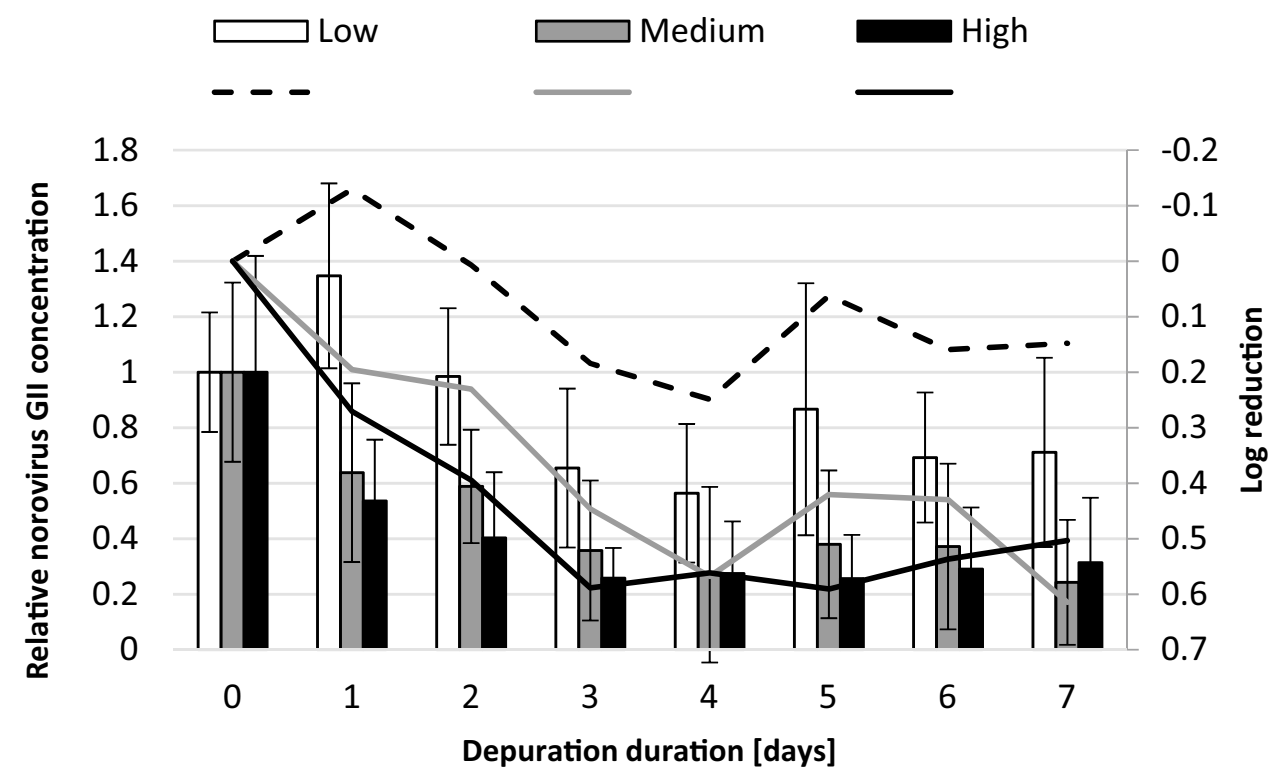

percussion. Mortality rates were comparable for the two oyster populations tested past week two, despite the different water temperature regimes used in depuration trials (paired $t$ test $p=0.3724)$.

\section{Evaluation of Commercial Depuration}

\section{Producer A Commercial Depuration Results}

A total of 13 paired samples (pre and post depuration) contaminated with norovirus GI, and 20 paired samples contaminated with norovirus GII, prior to depuration were identified from Producer A and included in this evaluation.
The geometric mean concentrations in the pre-depuration samples were $251 \mathrm{gcg}^{-1}$ and $281 \mathrm{gcg}^{-1}$ and maximum concentrations detected were 761 and $1658 \mathrm{gcg}^{-1}$ for norovirus GI and GII, respectively (Table 2). Following depuration, the geometric mean virus concentrations were $<$ LOQ for both genogroups with the maximum concentrations of norovirus GI and GII detected in any sample 468 and $300 \mathrm{gcg}^{-1}$, respectively. The difference in norovirus concentrations in oysters before and after depuration were found to be statistically significant for both genogroups (Mann-Whitney non-parametric $t$-test, $p<0.01$ and $p<0.001$, for norovirus GI and GII, respectively). A higher level of reduction was observed on average for norovirus GII compared to GI
Table 2 Norovirus GI and GII concentrations detected in oysters pre- and post-depuration collected from Producer A and $\mathrm{B}$

\begin{tabular}{|c|c|c|c|c|c|}
\hline \multirow{3}{*}{$\begin{array}{l}\text { Producer } \\
\text { Depuration conditions } \\
\text { Norovirus genogroup }\end{array}$} & \multicolumn{2}{|l|}{ A } & \multicolumn{3}{|l|}{ B } \\
\hline & \multicolumn{2}{|c|}{$12-16^{\circ} \mathrm{C}, 7$ days } & \multicolumn{3}{|l|}{$18^{\circ} \mathrm{C}, 3$ days } \\
\hline & GI & GII & GI & GII & $\mathrm{GII}^{\mathrm{a}}$ \\
\hline$n=$ & 13 & 20 & 20 & 13 & 12 \\
\hline \multicolumn{6}{|l|}{ Pre-depuration $\left[\mathrm{gcg}^{-1}\right]$} \\
\hline Average & 285 & 344 & 242 & 844 & 806 \\
\hline Geometric mean & 251 & 281 & 229 & 526 & 488 \\
\hline Min-Max & $150-761$ & $155-1658$ & $151-409$ & $167-2802$ & $167-2802$ \\
\hline \multicolumn{6}{|l|}{ Post-depuration $\left[\mathrm{gcg}^{-1}\right]$} \\
\hline Average & 121 & 65 & 129 & 317 & 158 \\
\hline Geometric mean & 82 & 45 & 91 & 66 & 49 \\
\hline Min-Max & $<$ LOD-468 & $<$ LOD-300 & $<$ LOD-366 & $<$ LOD-2232 & $<$ LOD $-780^{\mathrm{a}}$ \\
\hline Geometric mean reduction & $67.58 \%$ & $83.95 \%$ & $60.41 \%$ & $87.47 \%$ & $89.92 \%$ \\
\hline $\log _{10}$ reduction & 0.49 & 0.79 & 0.40 & 0.90 & 1.00 \\
\hline
\end{tabular}

$<$ LOD—results below the limit of detection $\left(<20 \mathrm{gcg}^{-1}\right.$ norovirus $\mathrm{GI},<20 \mathrm{gcg}^{-1}$ norovirus GII)

${ }^{a}$ Analysis results on an adjusted sample population, with one outlier pair, failing to reduce norovirus GII concentration in oysters during depuration, excluded from norovirus GII results 
(Table 2) where norovirus GII was reduced by $83.95 \%$ ( 0.79 $\log _{10}$ units) compared to $67.58 \%$ ( $0.49 \log _{10}$ units) reduction of norovirus GI.

\section{Producer B Commercial Depuration Results}

A total of 20 paired samples (pre- and post- depuration) contaminated with norovirus GI and 13 paired samples contaminated with norovirus GII were identified from Producer B and included in this evaluation. The geometric mean concentration in the pre-depuration samples were $229 \mathrm{gcg}^{-1}$ and $526 \mathrm{gcg}^{-1}$, for norovirus GI and GII, respectively (Table 2) with the maximum concentrations of 409 $\mathrm{gcg}^{-1}$ norovirus GI and $2802 \mathrm{gcg}^{-1}$ norovirus GII. Following depuration, the geometric mean virus concentrations were significantly reduced to $<$ LOQ for both norovirus GI and GII with maximum concentrations detected at $366 \mathrm{gcg}^{-1}$ norovirus GI and $2232 \mathrm{gcg}^{-1}$ norovirus GII. The difference in norovirus concentrations in oysters before and after depuration were found to be statistically significant for both genogroups (Mann-Whitney non-parametric $t$-test, $p<0.001$ and $p<0.05$ for norovirus GI and GII, respectively). In one of the 13 depuration runs analysed post depuration the concentration for norovirus GII $\left(2232 \mathrm{gcg}^{-1}\right)$ did not decrease from the pre-depuration concentration of 1304 norovirus GII $\mathrm{gcg}^{-1}$. On removal of this outlier pair the overall level of reduction demonstrated for norovirus GII was almost $90 \%$ or $1 \log _{10}$ units $(p<0.01)$. As observed for Producer A, a higher level of reduction was achieved for oysters contaminated with norovirus GII (87.47-89.92\% or $0.90-1.00 \log _{10}$ reduction) compared to norovirus GI ( $60.41 \%$ or $0.40 \log _{10}$ reduction), despite the different depuration conditions employed.

Overall in the commercial settings, there was a significant difference in the level of reduction between norovirus GI and GII $(p<0.001)$ where norovirus GI was reduced on average by $63.4 \%$ ( $0.43 \log _{10}$ units) compared to an on average reduction of $85.4 \%$ ( $0.84 \log _{10}$ units) for norovirus GII (Table 3). The extent of reduction to $<\mathrm{LOQ}$ also differed between genogroups when the pre-depuration concentrations were $<1000 \mathrm{gcg}^{-1}(p<0.05)$. In this instance $51.5 \%$ of samples contaminated with $<1000$ norovirus GI $\mathrm{gcg}^{-1}$ were reduced to $<$ LOQ post-depuration, whilst $78.6 \%$ of samples contaminated with $<1000$ norovirus GII gcg ${ }^{-1}$ were reduced to $<$ LOQ (Table 3). Samples contaminated with norovirus GII at concentrations $>1000 \mathrm{gcg}^{-1}$ prior to depuration were reduced to concentrations $<\mathrm{LOQ}$ in $40 \%$ of the cases. None of the samples examined in the commercial setting had concentrations of norovirus GI greater than $1000 \mathrm{gcg}^{-1}$.

\section{Discussion}

Norovirus contamination in oyster production areas is an ongoing issue for food safety regulators and oyster producers alike. The primary objective for both is the production of food that is safe for human consumption. Data published in a recent EFSA baseline survey highlights the high prevalence of norovirus contamination in oysters from classified production areas during the winter months (EFSA 2019). Peak norovirus concentration and prevalence was observed in the months of January and February when almost 65\% of samples tested were positive for norovirus with a mean concentration of $661 \mathrm{gcg}^{-1}$ (EFSA 2019). This important data demonstrates the need for effective mitigation measures to reduce norovirus concentrations before reaching the consumer. Whilst there are currently no legislative criteria for norovirus in oysters intended for consumption, there is recognition from international food safety regulators for the need to introduce such a criterion to protect consumers. Therefore, oyster producers need effective virus reduction measures in order to meet any such microbiological criterion for norovirus in the future. Previously, we demonstrated the potential of risk management procedures to reduce the risk of norovirus contamination in a production area as well as the reduction of norovirus concentrations in end-product by depuration (Rupnik et al. 2018). In that particular study extended depuration periods of up to 9 days were applied during the high-risk winter season. In addition, during that study minimum depuration temperatures were generally above the recommended minimum temperature of $8{ }^{\circ} \mathrm{C}$ (Anonymous 2018) with the mean temperature over all depuration cycles of $13.3{ }^{\circ} \mathrm{C}$ during the winter. This prompted further investigation of the ability of enhanced depuration conditions to reduce norovirus concentrations

Table 3 Overall efficacy of commercial norovirus GI and GII depuration in Pacific oysters based on all paired results from Producer A and B, combined

\begin{tabular}{lll}
\hline Norovirus genogroup & GI & GII \\
\hline Geometric mean reduction & $63.40 \%$ & $85.40 \%$ \\
$\log _{10}$ reduction & 0.43 & 0.84 \\
\hline Pre-depuration concentration & $\%$ Samples depurated to $<$ LOQ & 78.6 \\
\hline$<1000 \mathrm{gcg}^{-1}$ & 51.5 & 40.0 \\
$>1000 \mathrm{gcg}^{-1}$ & $\mathrm{n} / \mathrm{a}$ & 7 \\
\hline
\end{tabular}


in environmentally contaminated oysters destined for consumption. To our knowledge this is the first report of the application of a standardised test method (Anonymous 2017) to evaluate norovirus reduction during both, laboratory and commercial depuration processes to environmentally contaminated oysters.

The results of the laboratory depuration trials indicate that norovirus, whilst not completely removed, was significantly reduced when the water temperature used for depuration was increased to $>11^{\circ} \mathrm{C}$, but not at lower temperatures. Other studies have previously reported similar findings where norovirus was reduced, but not eliminated from contaminated shellfish, including clams, mussels and oysters (Ueki et al. 2007; Neish 2013; Polo et al. 2014a; Pilotto et al. 2019) using a variety of time and temperature combinations. The initial temporary increase in norovirus concentrations observed here at Day 1, and by others at Day 1-2 (McLeod et al. 2009; Polo et al. 2014c), could be explained by transient capture and subsequent release of norovirus particles from animal tissue outside of DT, such as gills and mantle (Maalouf et al. 2010). In addition, shellfish are known to slow down their metabolism and respiration rate at lower water temperatures (Dittman 1997; Li et al. 2017) and in such conditions relocation of virus particles from other tissues to DT and out as faeces or pseudofeces is less efficient and requires longer time.

The use of environmentally contaminated oysters in the depuration trials presented here, allowing for best representation of virus concentrations found in commercially harvested oysters, relied on long-term presence of the virus in environment in order to complete all planned experiments. Premature drop of norovirus GII concentration to levels below the critical lower limit (of $300 \mathrm{gcg}^{-1}$ ) experienced during this study resulted in lower number of depuration trials completed at medium water temperatures, compared to low or high water temperatures. While such an adequately balanced data set could have provided improved, more robust statistics, the data set obtained during this study provides statistically significant differences between the different temperature regimes studied. Additional depuration studies, focusing on the medium water temperatures of 11 to $15^{\circ} \mathrm{C}$ and using environmentally contaminated oysters, would be welcomed in the future to supplement the data presented here.

Initial viral load has been thought to have an impact on the depuration outcome whereby the higher the virus concentration prior to depuration, the higher the remaining virus load, if all other parameters were kept consistent (McLeod et al. 2017). The same finding was also observed in the study described here where oysters contaminated with $<1000$ norovirus GII $\mathrm{gcg}^{-1}$, were reduced to $<100$ $\mathrm{gcg}^{-1}$ in $1-4$ days. However, the same post-depuration concentrations were not achieved in oysters contaminated with higher virus concentrations $\left(>1000 \mathrm{gcg}^{-1}\right)$. This study has demonstrated the impact of the initial viral load prior to commencing depuration trials on the variability in concentrations observed especially in the early stages (day 1-3). Nevertheless, the concentrations detected after day 3 in the medium and high temperature trials in many of the samples were at or below the LOQ for norovirus GII. This emphasises the importance of having knowledge of the starting concentration of norovirus in oysters prior to depuration and should be a key consideration for operators who wish to reduce norovirus concentrations to levels that may be below any future microbiological criterion.

A two-phase reduction of norovirus in oysters was observed during the laboratory depuration trials, similar to that reported in clams and mussels (Polo et al. 2014c). In this study once the maximum reduction was achieved after day 3 and day 4 no further significant decline in virus concentrations took place. A slight fluctuation of norovirus concentrations were detected during the second reduction phase (i.e. post day 3/4) in some experiments particularly on day 5 and 6 . It is not clear what the exact cause is for these increases in virus concentration however it could be a reflection of the limitations of the RT-PCR method itself, especially when working with target concentrations close to, or below, the LOQ, a natural variability between samples or a potential re-contamination event due to sampling procedures. The optimal combination of time and temperature providing the most rapid reduction in norovirus was three days at the high temperature range with $74 \%\left(0.59 \log _{10}\right.$ units $)$ reduction observed. However, a similar final reduction occurred in the medium water temperature range albeit one day later (73\%, $0.57 \log _{10}$ units). More limited norovirus reduction was achieved during depuration at the low temperature with maximum reduction of $44 \%\left(0.25 \log _{10}\right.$ units $)$ observed after day 4 . The rate of reduction observed in the increased temperature trials (medium and high) were significantly different from that observed from the low temperature trials. This indicates that by setting depuration water temperature to $>11^{\circ} \mathrm{C}$ and by increasing the time allowed for depuration to 3-4 days, but not beyond, provides optimal reduction of norovirus from contaminated oysters whilst maintaining product shelf life.

To investigate norovirus reduction during depuration in the commercial setting we evaluated commercial practices undertaken by two separate oyster producers. Producer A employs longer depuration times (7 days) but lower water temperature (approximately $14{ }^{\circ} \mathrm{C}$ ), while Producer B minimises the depuration time ( 3 days) but maximises the temperature $\left(18^{\circ} \mathrm{C}\right)$. In both scenarios, similar levels of viral reduction for norovirus GI and GII were achieved despite the difference in time and temperature combinations (Table 3). As with the laboratory trials the concentration of norovirus in the pre-depuration samples was an important feature 
of the overall success of commercial norovirus reduction as judged by a target concentration of $<$ LOQ post-depuration. Almost four in five of all commercial oyster samples tested prior to depuration with a concentration $<1000 \mathrm{gcg}^{-1}$ norovirus GII contained concentrations $<$ LOQ post-depuration (Table 3 ). On the other hand, only $40 \%$ of samples with $>1000 \mathrm{gcg}^{-1}$ prior to depuration, were found to have concentrations $<$ LOQ for norovirus GII post-depuration. Despite a small number of commercial samples $(n=5)$ containing in excess of the $1000 \mathrm{gcg}^{-1}$ norovirus GII included in this evaluation, combined with findings from the laboratory designed trials, these results suggest that whilst enhanced depuration conditions can reduce norovirus concentrations in oysters, this only becomes an effective consumer health intervention strategy when the contamination in the oyster harvesting area is also managed. Applying enhanced depuration conditions to oysters that are contaminated to levels $>1000 \mathrm{gcg}^{-1}$, is unlikely to reduce norovirus concentrations to an acceptable level and will have limited public health benefit.

All but one laboratory depuration trial conducted at either medium or high water temperatures where the initial viral load in oysters was below $1000 \mathrm{gcg}^{-1}$ yielded concentrations $<$ LOQ after 4 days of depuration. In addition, one commercial depuration run (Producer B) also failed to reduce norovirus GII where the pre- and post-depuration concentration were similar. It is not clear what caused the poor depuration, or lack thereof, in these two instances but it does indicate that not all depuration runs will yield sufficient or similar reductions, despite consistent time and temperature conditions. This underlines the importance of monitoring the operation of commercial depuration systems to ensure reliable reduction of norovirus.

In both commercial depuration scenarios studied here the overall reduction rates were higher for norovirus GII than GI. Different behaviour between the viral strains during bioaccumulation and subsequent depuration have been reported previously (Nappier et al. 2008; Maalouf et al. 2011; Polo et al. 2014c) and could explain the differences observed here. Norovirus GI has been shown to bind to histo-blood like ligands in oyster digestive tissue, exhibiting prolonged persistence in oysters over GII norovirus indicating that its removal from oyster tissue may prove a greater challenge (Le Guyader et al. 2012). Laboratory trials as conducted for norovirus GII in this study are required for GI to fully elucidate the depuration kinetics for this genogroup. Unfortunately for the laboratory trials in this study, the production area from which the oysters were obtained does not have a history of regular norovirus GI contamination at concentrations suitable for such studies. Nonetheless, the results obtained from the commercial settings indicate the potential of enhanced depuration conditions to reduce norovirus GI concentrations to below the LOQ.
A greater reduction of norovirus GII was demonstrated in the commercial setting than in the laboratory trials with $84-87 \%\left(0.80-0.94 \log _{10}\right)$ reduction achieved by both commercial depuration processes compared with $74 \%(0.59$ $\log _{10}$ ) in laboratory trials. The improved reduction observed in the commercial setting could be caused by a number of factors particularly those that affect the condition of the oysters themselves. Depuration is a complex process despite the simplicity of the infrastructure required. Individual animals can respond differently to stress factors, such as sudden changes in temperature, salinity, lack of food and physical disturbance (shaking, transport or rough handling) (Lacoste et al. 2001; Marigómez et al. 2017; Peteiro et al. 2018; Seuront et al. 2019). Distressed animals may have trouble resuming normal filtration and therefore may fail to purge impurities. Indeed, in all the laboratory trials visual inspection confirmed that oysters resumed filtration within an hour from submerging in water, suggesting minimal disruption. However, it is possible that a few animals were under some degree of distress during harvest, transport, upon submerging into heated water or while collecting the daily samples. In contrast to the laboratory setting, where a portion of oysters were removed from each depuration tank daily potentially unsettling the oyster population, the commercial depuration tanks were left undisturbed for the full duration of depuration (either 3 or 7 days). The tanks were drained once the process was completed and only then the oysters were removed, and the final post-depuration sample taken for analysis. This suggests the need for minimal handling and disturbance of the oysters during the depuration process to ensure greatest reduction.

Many studies investigating norovirus removal or reduction from bivalves have involved contaminating various shellfish species through bioaccumulation. Such laboratory contamination can result in very high starting concentrations which may not be reflective of concentrations naturally found in bivalves, especially oysters. Here, we used environmentally contaminated oysters from approved production areas to study norovirus reduction. Therefore, this represented concentrations of norovirus found in oysters prior to post-harvest treatment and destined for human consumption. The concentration prior to depuration in both the laboratory and commercial settings was significantly higher than the concentrations measured after depuration once the water temperature was $>11^{\circ} \mathrm{C}$. Of course, the question remains surrounding the public health significance of these remaining norovirus concentrations due to the lack of a routine norovirus infectivity assay despite promising developments with the human enteroid system (Ettayebi et al. 2016; Costantini 2018). The illness outcome for any given norovirus concentration in contaminated oysters will depend on the norovirus genotype, which could be single or multiple, the immune and genetic susceptibility of a host (Noda et al. 
2008), as well as the size and number of oysters ingested by the consumer. However, a link between increasing number of virus genome copies detected and risk of infection has been reported previously (Lowther et al. 2012). A low likelihood of outbreaks was shown to be associated with oysters containing norovirus in concentrations below 100 $\mathrm{gcg}^{-1}$, levels readily achievable in this study in the depuration trials using increased water temperature and times. Hunt et al. (2020) demonstrated that norovirus GII was found to be log-normally distributed across individual animals within a population and that for mean concentrations below 100 $\mathrm{gcg}^{-1}$ it was likely that some of the oysters in the tested population contain no or very little amount of virus ( $<$ LOD). In contrast, all oysters in the tested population were found to be contaminated when the mean concentration tested above 300 $\mathrm{gcg}^{-1}$ (Hunt 2019). Additionally, two recent studies investigated the FRNA bacteriophage type II (norovirus surrogate) removal from oysters during depuration using genomic and infectivity methods (Leduc et al. 2020; Younger et al. 2020). These studies indicated that viruses may either be inactivated in oysters during depuration (Leduc et al. 2020) or, as suggested by Younger et al. (2020), destroyed and removed. Despite the differences in the concluded viral reduction mechanisms these findings could indicate that the virus genome copies detected using RT-PCR methods are, at least in part, only footprints left by the infectious virus particles and they no longer have the capability of causing infection especially at low concentrations (i.e. $\leq \mathrm{LOQ}$ ).

A recently published EFSA baseline survey provides comprehensive scientific data for norovirus prevalence in European oyster harvesting areas and will form the basis for discussion amongst EU authorities attempting to place a safety limit on norovirus concentration in oysters. Should a regulatory microbiological criterion for norovirus arise, reduction strategies such as enhanced depuration as described in this study may become an important intervention measure for food business operators to successfully comply with such a criterion. The application of enhanced depuration conditions, taking into consideration time and temperature, to environmentally contaminated oysters provides a practical tool for oyster producers enabling the reduction of norovirus concentrations to levels that reduce, if not eliminate, the risk to consumers. This study applied a standardised test method (Anonymous 2017) to verify norovirus reduction in both laboratory and commercial depuration trials providing reliable and robust data. Additionally, data arising from these experiments could be applied to mathematical prediction models, such as that developed by McMenemy et al. (2018) to predict the minimum time required to depurate norovirus to desired concentrations. Effectiveness of such forecasting models depends on comprehensive and reliable data. The combined effort of enhanced depuration for norovirus removal and reliable monitoring using a standardised method for detection of norovirus in shellfish may provide an important risk management tool for the oyster industry in light of potential forthcoming legislation.

Funding This study was funded by Department of Agriculture, Food and the Marine (Grant No. 14/SF/852).

Open Access This article is licensed under a Creative Commons Attribution 4.0 International License, which permits use, sharing, adaptation, distribution and reproduction in any medium or format, as long as you give appropriate credit to the original author(s) and the source, provide a link to the Creative Commons licence, and indicate if changes were made. The images or other third party material in this article are included in the article's Creative Commons licence, unless indicated otherwise in a credit line to the material. If material is not included in the article's Creative Commons licence and your intended use is not permitted by statutory regulation or exceeds the permitted use, you will need to obtain permission directly from the copyright holder. To view a copy of this licence, visit http://creativecommons.org/licenses/by/4.0/.

\section{References}

Alfano-Sobsey, E., Sweat, D., Hall, A., Breedlove, F., Rodriguez, R., Greene, S., et al. (2011). Norovirus outbreak associated with undercooked oysters and secondary household transmission. Epidemiology and Infection, 28, 1-7.

Anonymous. (2004). Regulation (EC) 854/2004 of the European Parliament and of the Council of 29 April 2004 laying down specific rules for the organisation of official controls on products of animal origin intended for human consumption.

Anonymous. (2017). ISO 15216-1:2017 Microbiology of food and animal feed-horizontal method for determination of hepatitis A virus and norovirus in food using realtime RT-PCR-Part 1: method for quantification. International Organization for Standardization, Geneva, pp 15216-1

Anonymous. (2018). SFPA Guidance Document for Inspecting LBM Purification Centres. Ref: Regulation (EC) 853/2004 Annex III Section VII

Anonymous. (2019). Commission implementing regulation (EU) 2019/ 627-of 15 March 2019-laying down uniform practical arrangements for the performance of official controls on products of animal origin intended for human consumption in accordance with Regulation (EU) 2017/ 625 of the European Parliament and of the Council and amending Commission Regulation (EC) No 2074 / 2005 as regards official controls

Baker, K., Morris, J., McCarthy, N., Saldana, L., Lowther, J., Collinson, A., \& Young, M. (2010). An outbreak of norovirus infection linked to oyster consumption at a UK restaurant. Journal of Public Health, 33(2), 205-211.

Bellou, M., Kokkinos, P., \& Vantarakis, A. (2013). Shellfish-borne viral outbreaks: A systematic review. Food and Environmental Virology, 5(1), 13-23. https://doi.org/10.1007/s12560-012-9097-6.

CEFAS (2016) (EURL for monitoring bacteriological and viral contamination of bivalve molluscs). Guidance note for the determination of limit of detection (LOD95) and limit of quantification (LOQ) characteristics for the method for quantification of norovirus in oysters. Retrieved from https://eurlcefas.org/media/13957/ lod-and-loq-guidance-note-v2.pdf.

Chalmers, J. W., \& McMillan, J. H. (1995). An outbreak of viral gastroenteritis associated with adequately prepared oysters. Epidemiology and Infection, 115(1), 163-167. 
Choi, S., \& Jiang, S. C. (2005). Real-time PCR quantification of human adenovirus in urban rivers indicates genome prevalence but low infectivity. Applied and Environmental Microbiology, 71(11), 7426-7433.

Costafreda, M. I., Bosch, A., \& Pintó, R. M. (2006). Development, evaluation, and standardization of a real-time TaqMan reverse transcription-PCR assay for quantification of hepatitis A virus in clinical and shellfish samples. Applied and Environmental Microbiology, 72(6), 3846-3855.

Costantini, A. (2018). Human norovirus replication in human intestinal enteroids as model to evaluate virus inactivation. Emerging Infectious Diseases Journal. https://doi.org/10.3201/eid2408.180126.

da Silva, A. K., Le Saux, J. C., Parnaudeau, S., Pommepuy, M., Elimelech, M., \& Le Guyader, F. S. (2007). Evaluation of removal of noroviruses during wastewater treatment, using real-time reverse transcription-PCR: Different behaviours of genogroups I and II. Applied and Environmental Microbiology, 73(24), 7891-7897.

Dittman, D. E. (1997). Latitudinal compensation in oyster ciliary activity. Functional Ecology, 11(5), 573-578. https://doi.org/10.104 6/j.1365-2435.1997.00127.x.

Doré, W. J., Henshilwood, K., \& Lees, D. N. (1998). The development of management strategies for control of virological quality in oysters. Water Science and Technology, 38(12), 29-35.

Doré, W. J., Keaveney, S., Flannery, J., \& Rajko-Nenow, P. (2010). Management of health risk associated with oysters harvested from a norovirus contaminated area, Ireland, February-March 2010. EuroSurveillance, 15(19), 1-5.

EFSA. (2019). Analysis of the European baseline survey of norovirus in oysters. EFSA Journal, 17(7), e05762. https://doi.org/10.2903/j. efsa.2019.5762.

Ettayebi, K., Crawford, S. E., Murakami, K., Broughman, J. R., Karandikar, U., Tenge, V. R., et al. (2016). Replication of human noroviruses in stem cell-derived human enteroids. Science, 353, 1387-1393.

Flannery, J., Keaveney, S., Rajko-Nenow, P., O'Flaherty, V., \& Doré, W. J. (2012). Concentration of norovirus during wastewater treatment and its impact on oyster contamination. Applied and Enviromental Microbiology, 78(9), 3400-3406.

Hoehne, M., \& Schreier, E. (2006). Detection of Norovirus genogroup I and II by multiplex real-time RT- PCR using a 3'-minor groove binder-DNA probe. BMC Infectious Diseases. https://doi. org/10.1186/1471-2334-6-69.

Hunt, K. (2019). A risk assessment of norovirus in irish produced raw oysters. PhD thesis, UCD

Hunt, K., Doré, W., Keaveney, S., Rupnik, A., \& Butler, F. (2020). Estimating the distribution of norovirus in individual oysters. International Journal of Food Microbiology, 333, 108785. https ://doi.org/10.1016/j.ijfoodmicro.2020.108785.

Kageyama, T., Kojima, S., Shinohara, M., Uchida, K., Fukushi, S., Hoshino, F. B., et al. (2003). Broadly reactive and highly sensitive assay for Norwalk-like viruses based on real-time quantitative reverse transcription-PCR. Journal of Clinical Microbiology, 41(4), 1548-1557.

Kingsley, D. H., Meade, G. K., \& Richards, G. P. (2002). Detection of both Hepatitis A virus and Norwalk-like virus in imported clams associated with food-borne illness. Applied and Environmental Microbiology, 68(8), 3914-3918.

Lacoste, A., Malham, S. K., Cueff, A., \& Poulet, S. A. (2001). Stressinduced catecholamine changes in the hemolymph of the oyster Crassostrea gigas. General and Comparative Endocrinology, 122(2), 181-188. https://doi.org/10.1006/gcen.2001.7629.

Le Guyader, F. S., Atmar, R. L., \& Le Pendu, J. (2012). Transmission of viruses through shellfish: When specific ligands come into play. Current Opinion in Virology, 2(1), 103-110.

Le Guyader, F. S., Krol, J., Ambert-Balay, K., Ruvoen-Clouet, N., Desaubliaux, B., Parnaudeau, S., et al. (2010). Comprehensive analysis of a norovirus-associated gastroenteritis outbreak, from the environment to the consumer. Journal of Clinical Microbiology, 48(3), 915-920. https://doi.org/10.1128/jcm.01664-09.

LeBlanc, J. J., Pettipas, J., Gaston, D., Taylor, R., Hatchette, T. F., Booth, T. F., et al. (2016). Outbreak of norovirus GII.P17-GII.17 in the Canadian Province of Nova Scotia. Canadian Journal of Infectious Diseases and Medical Microbiology, 2016, 1-6. https ://doi.org/10.1155/2016/1280247.

Leduc, A., Leclerc, M., Challant, J., Loutreul, J., Robin, M., Maul, A., et al. (2020). F-specific RNA bacteriophages model the behavior of human noroviruses during purification of oysters: The main mechanism is probably inactivation rather than release. Applied and Environment Microbiology. https://doi.org/10.1128/ AEM.00526-20.

Lee, T., Yam, W. C., Tam, T.-Y., Ho, B. S. W., Ng, M. H., \& Broom, M. J. (1999). Occurrence of hepatitis A virus in green-lipped mussels (Perna viridis). Water Research, 33(3), 885-889. https ://doi.org/10.1016/S0043-1354(98)00269-3.

Lees, D., Younger, A., \& Dore, B. (2010). Depuration and relaying. In G. Rees, K. Pond, D. J. B. Kay, \& J. Santo Domingo (Eds.), Safe management of shellfish and harvest waters. London: International Water Association.

Li, A., Li, L., Song, K., Wang, W., \& Zhang, G. (2017). Temperature, energy metabolism, and adaptive divergence in two oyster subspecies. Ecology and Evolution, 7(16), 6151-6162. https:// doi.org/10.1002/ece3.3085.

Loisy, F., Atmar, R. L., Guillon, P., Le Cann, P., Pommepuy, M., \& Le Guyager, F. S. (2005). Real-time RT-PCR for norovirus screening in shellfish. Journal of Virological Methods, 123, 1-7.

Lowther, J. A., Gustar, N. E., Hartnell, R. E., \& Lees, D. N. (2012). Comparison of norovirus RNA levels in outbreak-related oysters with background environmental levels. Journal of Food Protection, 75(2), 389-393.

Maalouf, H., Schaeffer, J., Parnaudeau, S., Le Pendu, J., Atmar, R. L., Crawford, S. E., \& Le Guyader, F. S. (2011). Straindependent norovirus bioaccumulation in oysters. Applied and Environmental Microbiology, 77(10), 3189-3196.

Maalouf, H., Zakhour, M., Le Pendu, J., Le Saux, J. C., Atmar, R. L., \& Le Guyader, F. S. (2010). Distribution in tissue and seasonal variation of norovirus genogroup I and II ligands in oysters. Applied and Environmental Microbiology, 76(16), 5621-5630. https://doi.org/10.1128/aem.00148-10.

Marigómez, I., Múgica, M., Izagirre, U., \& Sokolova, I. M. (2017). Chronic environmental stress enhances tolerance to seasonal gradual warming in marine mussels. PLOS ONE, 12(3), e0174359. https://doi.org/10.1371/journal.pone.0174359.

Marshall, J. A., \& Bruggink, L. D. (2011). The dynamics of norovirus outbreak epidemics: Recent insights. IJERPH, 8(4), 11411149. https://doi.org/10.3390/ijerph8041141.

Marshall, J. A., Hellard, M. E., Sinclair, M. I., Fairley, C. K., Cox, B. J., Catton, M. G., et al. (2003). Incidence and characteristics of endemic norwalk-like virus-associated gastroenteritis. Journal of Medical Virology, 69, 568-578.

McLeod, C., Hay, B., Grant, C., Greening, G., \& Day, D. (2009). Inactivation and elimination of human enteric viruses by Pacific oysters. Journal of Applied Microbiology, 107(6), 1809-1818. https://doi.org/10.1111/j.1365-2672.2009.04373.x.

McLeod, C., Polo, D., Le Saux, J. C., \& Le Guyader, F. S. (2017). Depuration and relaying: A review on potential removal of norovirus from oysters. Comprehensive Reviews in Food Science and Food Safety. https://doi.org/10.1111/1541-4337.12271.

McMenemy, P., Kleczkowski, A., Lees, D. N., Lowther, J., \& Taylor, N. (2018). A model for estimating pathogen variability in shellfish and predicting minimum depuration times. PLOS ONE, 13(3), e0193865. https://doi.org/10.1371/journal.pone.0193865. 
Morse, D. L., Guzewich, J. J., Hanrahan, J. P., Stricof, R., Shayegani, M., Deibel, R., et al. (1986). Widespread outbreaks of clamand oyster-associated gastroenteritis. New England Journal of Medicine, 314(11), 678-681. https://doi.org/10.1056/NEJM1 98603133141103.

Muniain-Mujika, I., Girones, R., Tofiño-Quesada, G., Calvo, M., \& Lucena, F. (2002). Depuration dynamics of viruses in shellfish. International Journal of Food Microbiology, 77(1-2), 125-133.

Nappier, S. P., Graczyk, T. K., \& Schwab, K. J. (2008). Bioaccumulation, retention, and depuration of enteric viruses by crassostrea virginica and crassostrea ariakensis oysters. AEM, 74(22), 6825-6831. https://doi.org/10.1128/AEM.01000-08.

Neish, A. (2013). Investigative trials on the purification of oysters to identify ways of reducing norovirus. Lowestoft: CEFAS report.

Noda, M., Fukuda, S., \& Nishio, O. (2008). Statistical analysis of attack rate in norovirus foodbourne outbreaks. International Journal of Food Microbiology, 122, 216-220.

Peteiro, L. G., Woodin, S. A., Wethey, D. S., Costas-Costas, D., Martínez-Casal, A., Olabarria, C., \& Vázquez, E. (2018). Responses to salinity stress in bivalves: Evidence of ontogenetic changes in energetic physiology on Cerastoderma edule. Scientific Reports, 8(1), 8329. https://doi.org/10.1038/s41598-018-26706-9.

Pilotto, M. R., Souza, D. S. M., \& Barardi, C. R. M. (2019). Viral uptake and stability in Crassostrea gigas oysters during depuration, storage and steaming. Marine Pollution Bulletin, 149, 110524. https://doi.org/10.1016/j.marpolbul.2019.110524.

Pintó, R. M., Costafreda, M. I., \& Bosch, A. (2009). Risk assessment in shellfish-borne outbreaks of hepatitis A. Applied and Environmental Microbiology, 75(23), 7350-7355.

Polo, D., Alvarez, C., Diez, J., Darriba, S., Longa, A., \& Romalde, J. L. (2014a). Viral elimination during commercial depuration of shellfish. Food Control, 43, 206-212. https://doi.org/10.1016/j. foodcont.2014.03.022.

Polo, D., Álvarez, C., Vilariño, M. L., Longa, Á., \& Romalde, J. L. (2014b). Depuration kinetics of hepatitis A virus in clams. Food Microbiology, 39, 103-107. https://doi.org/10.1016/j. fm.2013.11.011.

Polo, D., Feal, X., Varela, M. F., Monteagudo, A., \& Romalde, J. L. (2014c). Depuration kinetics of murine norovirus in shellfish. Food Research International, 64, 182-187. https://doi. org/10.1016/j.foodres.2014.06.027.

Rajko-Nenow, P., Keaveney, S., Flannery, J., McIntyre, A., \& Dore, W. (2013). Norovirus genotypes implicated in two oyster-related illness outbreaks in Ireland. Epidemiology and Infection, 142(10), 2096-2104. https://doi.org/10.1017/S0950268813003014.

Rupnik, A., Keaveney, S., Devilly, L., Butler, F., \& Doré, W. (2018). The impact of winter relocation and depuration on norovirus concentrations in pacific oysters harvested from a commercial production site. Food and Environmental Virology. https://doi. org/10.1007/s12560-018-9345-5.

Schwab, K. J., Neill, F. H., Estes, M. K., Metcalf, T. G., \& Atmar, R. L. (1998). Distribution of Norwalk virus within shellfish following bioaccumulation and subsequent depuration by detection using RT-PCR. Journal of Food Protection, 61(12), 1674-1680.

Seuront, L., Nicastro, K. R., Zardi, G. I., \& Goberville, E. (2019). Decreased thermal tolerance under recurrent heat stress conditions explains summer mass mortality of the blue mussel Mytilus edulis. Sci Rep, 9(1), 17498. https://doi.org/10.1038/s41598-01953580-w.

Souza, D. S. M., Dominot, A. F. Á., Moresco, V., \& Barardi, C. R. M. (2018). Presence of enteric viruses, bioaccumulation and stability in Anomalocardia brasiliana clams (Gmelin, 1791). International Journal of Food Microbiology, 266, 363-371. https://doi. org/10.1016/j.ijfoodmicro.2017.08.004.

Souza, D. S. M., Piazza, R. S., Pilotto, M. R., de do Nascimento, A. A., Moresco, V., Taniguchi, S., et al. (2013). Virus, protozoa and organic compounds decay in depurated oysters. International Journal of Food Microbiology, 167(3), 337-345. https://doi. org/10.1016/j.ijfoodmicro.2013.09.019.

Svraka, S., Duizer, E., Vennema, H., de Bruin, E., van de Veer, B., Dorresteijn, B., \& Koopmans, M. (2007). Etiological role of viruses in outbreaks of acute gastroenteritis in The Netherlands from 1994 through 2005. Journal of Clinical Microbiology, 45(5), 1389-1394.

Ueki, Y., Shoji, M., Suto, A., Tanabe, T., Okimura, Y., Kikuchi, Y., et al. (2007). Persistence of caliciviruses in artificially contaminated oysters during depuration. AEM, 73(17), 5698-5701. https ://doi.org/10.1128/AEM.00290-07.

Westrell, T., Dusch, D., Ethelberg, H. J., Hjertqvist, M., Jourdan-daSilva, N., Koller, A., et al. (2010). Norovirus outbreaks linked to oyster consumption in the United Kingdom, Norway, France, Sweden and Denmark 2010. Euro Surveillance, 15(12), 8-11.

Younger, A. D., Neish, A., Walker, D. I., Jenkins, K. L., Lowther, J. A., Stapleton, T. A., \& Alves, M. T. (2020). Strategies to reduce norovirus (NoV) contamination from oysters under depuration conditions. Food and Chemical Toxicology. https://doi.org/10.1016/j. fct.2020.111509.

Publisher's Note Springer Nature remains neutral with regard to jurisdictional claims in published maps and institutional affiliations. 